\title{
Who Owns the Patient? an Examination of the Concept of Own- ership in Health Care Ethics
}

\section{Kalada Godson McFubara*}

Department of Community Medicine, Niger Delta University, Wilberforce Island, Bayelsa State, Nigeria

"Corresponding author: Kalada Godson McFubara, Department of Community Medicine, Faculty of Clinical Sciences, Niger Delta University, Wilberforce Island, Bayelsa State, Nigeria. Tel: +2348037109228; Email: kaladamcfubara@gmail.com

Citation: McFubara KG (2018) Who Owns the Patient? An Examination of the Concept of Ownership in Health Care Ethics. J Hosp Health Care Admin: JHHA-110. DOI: 10.29011/JHHA-110. 00010

Received Date: 15 January, 2018; Accepted Date: 06 February, 2018; Published Date: 15 February, 2018

\begin{abstract}
Summary
Despite the health sector being multidisciplinary, the medical profession alone claims ownership of the patient. In this paper an analysis of the concept of ownership in the context of the patient's protection, was conducted. The aim was to identify the ethical implication of the concept. The result shows that by its unilateral claim of ownership of the patient the medical profession is still paternalistic rather than being a partner in the relationship between it and the patient. However, the paper shows that only the patient is his own owner. It means that a claim of ownership of the patient by any health profession is unethical. This is because health sector workers provide service with the consent of (a contractual agreement with) their patient or employer. Therefore, no professional group has the moral authority to claim ownership of that which they are hired to service or protect. There is need also for the health professions to review their pledges or the oath they take at induction by adopting the patient instead of my patient. This would ensure the recognition of the patient as his own owner, who must also be respected.
\end{abstract}

Keywords: Altruism; Authority; Consultant; Hospital; Health Profession; Patient protection

\section{Introduction}

The health sector is multidisciplinary or multi-professional. But at the hospital setting any two key professions that have direct contact with patients must include the medical and nursing professions. Thus in 2014 during one of many industrial strikes embarked upon by the health workers in Nigeria, it was curious to read the President of the Nigerian Medical Association (NMA) claim "a consultant is the owner of the patient" [1]. There are a couple of ways to address the curiosity in the claim. One is to suggest that to be a consultant in a hospital setting means that one is the owner of the patient, even though the patient is the basis for the duty of care for all who are saddled with that duty. A second suggestion is that as the most senior professional in a health team the primary responsibility for care of the patient rests with the consultant while others are mere assistants. Of course, this does not mean the other professions are deputies to the medical profession. However, in whichever way one looks at the matter it is tantamount to arouse conflict between the other health care professions and the medical profession on the one hand and among the members of the medical profession (e.g. between the consultants and the other doctors) on another hand. For the other professions a conflict can arise because all the professions have their respective allegiance to themselves (their professional councils), not the others to one. For the medical profession a conflict can arise even if unspoken because in the Hippocratic Oath, all doctors identify the patient as "my patient". Taking all these into consideration it appears that the business of health care (medical) ethics which really devolves around the patient's rights and responsibilities as well as the duties of the doctor to the patient, the public and the profession is misunderstood and misapplied.

Brock and Saks [2] observe that other authors have shown that professions like the medical profession have used exclusionary social closure as propounded by Max Weber to ensure that state underwritten occupational monopoly in the health sector is to their advantage. For instance, Parkin [3] believes that these professions have used such monopoly to increase their income, status and power [2]. Although it is argued that the position of the hospital consultant is professional which members of any profession can aspire to attain, the medical profession in their monopoly of the position of the Minister or Commissioner for Health has consistently and successfully resisted other professions from taking the position of 


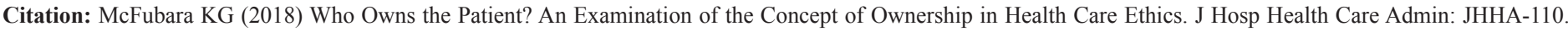
DOI: $10.29011 /$ JHHA-110. 00010

consultant within the hospital setting. The problem here however is that health care professionals have failed to understand that their various professions evolved or differentiated from health care and not from medical care. It is also often forgotten that there was a time in history when the services of the physician, the nurse and the pharmacist were all combined in one practitioner. But if one of these professions has become the 'super-profession' that can do without the others in the health professional order, it should not be a reason for a domineering posturing over the others. There is no reason to think that is the case for now. But if one profession has fear that other health professions may also lay claim to ownership of the patient, the question then is, who is the patient to warrant ownership claim by one health profession and not the other? In this paper the concept of ownership is examined. That examination forms the basis for a moral philosophical discussion on the role of the consultant and altruism in health care practice. It is hoped that this will address issues of inter- or even intra- professional conflicts so as to ensure and maintain the patient's safety and dignity.

\section{Who is a Patient?}

The health care sector is not like the legal sector where the professionals are in contest for clients, often adversarial, with each other. Although the word client has crept into the health care business, the authentic word for the client in the health sector is the patient. The Mosby's Medical, Nursing and Allied health dictionary [4] defines a patient as someone who is a recipient of health care within or outside a hospital setting. This means that there may be illness or there may not be illness. Thus health care can be seen to restore, to improve or to maintain normalcy in the physical, social or psychological conditions of the human person. Health care is therefore a service not only provided by the doctor, who is currently the only officer within the Nigerian hospital setting titled as a consultant, but also by other professions outside the hospital setting. In On Moral Medicine, Jensen [5] writes that man as patient is seen by the physician from two perspectives. In one perspective the physician sees the patient (man) as an object to be repaired and in the other perspective the patient (man) is the physician's fellow man. In fact, the nature of man is such that he is his own owner. This is captured in Rahner [6] where the author observed that "man is characteristically the being that has been handed over to himself, consigned to his free responsibility." The word repair here can mean more than one thing including to care for, to maintain, to restore etc. Hence viewing the issue of health care from both perspectives Jenson adds that the moral and religious involvement of the patient (in the course of this care) must be dealt with and supported. This is achieved by showing visible respect to the patient and giving room for his consent to treatment.

Talking about support Jenson further observed that the health giving value of these aspects of involvement of the patient does not transcend the perspectives of the doctor. By this the author means that the doctor as a technician of the behavioral sciences does the thinking while the patient obeys his directives. But this also goes to imply that the job of physical repair of the patient is not the sole responsibility of the doctor as it would also include psychological and social repair which however can also be undertaken by others even non-medical practitioners. Meanwhile in the various health professional pledges and oaths it is only the Physician Oath that talks about "my patient". Others talk about "the patient" (Pharmacist's Oath for instance), or just "patients" and "the general public" (in the Florence Nightingale Pledge and the Code of Professional Conduct of the Medical Laboratory Council of Nigeria). These differences invariably mean that only the doctor can be expected to see or take the patient as his own, thereby to carry much of the burden of care of the patient. But even at that for the doctor to be justified in the claim for ownership of the patient he would need the cooperative support of other health professions and the partnership of the patient as his fellow man.

\section{The Concept of Ownership}

To own something means that the thing belongs to the one making the claim of ownership. The concept is therefore possessive to oneself and not to any other. In law although the concept has been defined differently in jurisprudence many authors like Sir John William Salmond, John Austin and William Nembhard Hibbert agree that ownership is the complete and supreme right to the possession of a thing or an object (www.legalservicesindia. com/articles/ownership_1281-.html). This can be illustrated in the fact that the right to possessive ownership does not cease in death but is passed on to heirs. But the concept could also be used just for identification with the one making the claim. For instance, when one says 'it is his own patient that did it', one is simply identifying the patient with a particular care provider. Here ownership if at all is protective. Furthermore, when the concept is used in the sense that connotes belonging it can be likened to a situation where attempt is made to avoid patient pouching or encroachment into another's duty base. This was the case among medical practitioners at the time of the early development of medical ethics. Even at present intra-professionally especially within the medical profession, in the name of trying to avoid encroachment, ownership of the patient in the first sense of the meaning of the word is being strongly but silently claimed and practiced. To illustrate this is the case of Harold Shipman, the killer doctor [7], who took advantage of this to claim inheritance of the property of the patients in his care after killing them. The other sense of the concept is that when a man hands over his car for repair he does not transfer ownership of the car to his mechanic nor does the mechanic claim ownership of the vehicle. It is in this sense of the concept that the patient hands over himself (not ownership of himself) to the doctor for repair (healing). 


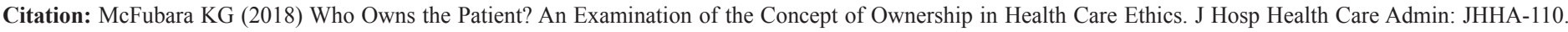
DOI: $10.29011 /$ JHHA-110. 00010

\section{Authority and Ownership}

From the above interpretative perspective of the claim by the NMA President and the concept of authority which suggest that the consultant has control over the other professionals in their duty of care to patients, Thomas Hobbes [8] observes "He that owneth his words and actions is the AUTHOR: in which case the actor acteth by authority .....". This means that the care giver gives care only by consent or authority of the care receiver. In other words, an adult owner of a thing cannot require authority to access what he owns. If it were not so then something must be wrong especially when the Common Law affirms bodily integrity of an adult individual and prohibits even unauthorized touching of the patient in the doctrine of assault and battery. The same is buttressed by Uzodike [9] who observed that the relationship between doctor and patient has moved from being paternalistic to partnership. This is because paternalism which sees the patient irrespective of age and knowledge, as a child, [10] cannot be protecting the patient's best interest. The patient therefore can be more altruistically owned by nobody other than himself who also has the power to give consent for his own care. In essence even professional altruism cannot confer authority or claim of ownership to the professional because according to Hauerwas 'all relations that are less than fully voluntary [are] morally suspect' [8]. Such is the case in health care that Sulmasy having examined the various models of authority observes that because there are many and confusing meanings of authority, the relationship between doctor and patient has become understood as a struggle for power, where power is "the ability to control and be free from control of others" [8]. It is important to be clear about this in order to avoid unnecessary inter-professional as well as intra-professional conflict and distrust in the doctor patient relationship. This clarity would deepen the understanding of the protection of the patient's interest as the main goal in health care practice rather than the protection of professional interest or the protection of professional monopoly of authority and/or ownership which is suggested in the claim for ownership of the patient by the medical profession. Therefore, if there would be any sense of ownership of the patient at all, Maxson [11] summarizes it in her account on the film "Whose Life is It Anyway?" and concluded that it is all of ours.

Meanwhile possessive ownership, that is, having ownership should not be mistaken for taking ownership. In the latter case the one taking ownership is filling a responsibility space not being fulfilled by any other. Thus in a team where the consultant is the formal leader the individual can take ownership of the particular care of a patient who is not being cared for. That means that in a team of doctors or even different professions, as it is indicated by the General Medical Council of Britain, the leader is only accountable for the performance of the team [12]. However, the responsibility for identifying problems, solving them and taking appropriate decisions is shared by the team as a whole with neither member claiming to have ownership of the one being cared for.

\section{The Role of the Consultant}

When all the above are considered in the light of how the patient has been treated especially when there is a misunderstanding or disagreement between employers and employees in the health care sector, the concept of ownership in the context of the role of the consultant and the patient's protection calls for self-examination. For instance, is it that to be a consultant one has to be the owner of the patient and that guarantees the patient's protection? On the other hand, is it that being a consultant makes one the owner of the patient and therefore the consultant is responsible for the patient's protection? Both perspectives of the consultant are possessive and as at the time of the NMA President's comment it is only members of the NMA that have their personnel in the hospital setting recognized up to the rank of consultant. Other hospital based health care professional associations have been demanding for the same recognition but the NMA has been resisting it in the fear that it would cause confusion among patients. That fear is unfounded because in the university system lecturers in all disciplines can become professors without confusion arising among the students. In fact, the concept of consultant is being adopted by many professionals and experts and they are recognized by governments, their agencies and non-governmental organizations, local and foreign. This is because by the definition of the Concise Oxford Dictionary, a consultant can be any one providing professional advice for fee (this fits into the context described in the last sentence) or a consultant is a senior specialist in a branch of medicine recognized by a medical post graduate college and is leader of the team providing care to a patient in a hospital setting. Therefore, taking from the first definition above there is no specific place designated where a consultant is limited to function. That leaves not only health care providers but anyone who wishes to be so identified, as being entitled to the designation of a consultant wherever they may be. But the second definition above seems to limit the appellation of consultant not even to all doctors but only to those doctors who have been appropriately trained to function as such within the higher level dictates of medical education and practice.

\section{Why is the Claim for Ownership of the Patient?}

Is the claim for ownership being made on the grounds of full responsibility for protection of the patient even if it be for the temporary period the patient is in the hospital or is it for the full responsibility for protection over the patient for all the time of being a patient? Can there be protection for the patient in a multidisciplinary work place when one profession lays claim to ownership of the patient, the object of duty of care of all the professions? In the light of the context of the NMA president's claim 


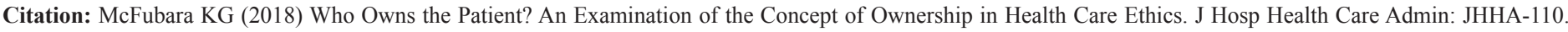
DOI: $10.29011 /$ JHHA-110. 00010

it may appear that it was for the full responsibility of protection over the patient. But the health sector being a multidisciplinary sector means that each profession has specific role to play in health care delivery. Never the less all professions within the sector have a collective responsibility for protection over the patient. Safety of the patient should therefore be a mutually inclusive responsibility among the professions. To suggest otherwise may put the patient's safety and protection in jeopardy.

Vestappen et al. [13] conducted a wide review of literature on patient safety by using online Delphi procedure. In the review the authors identified patient involvement and prospective risk analysis as two promising and innovative strategies for improving patient safety in primary care. But in a multidisciplinary sector with incessant strike actions and attendant professional rivalry, one profession claiming ownership of the patient leaves the patient involvement in issues that concerns his safety difficult to achieve. In fact, the review found that poor teamwork and suboptimal handover of patient are contributory to patient safety problems. There is also the problem of safety incident reporting. In a similar review of literature on incident reporting system, Klemp et al. [14] identified features to include purpose of reporting and who should be involved in reporting. If the Nigerian consultant is the owner of the patient, in the context of this discussion he would be reluctant to report safety incident in his domain. But it was the culture of silence which has had damaging effect on patient safety that informed the Brigham and Women Hospital in the United States to begin the publication of Safety Matters in 2011. This was in a bid to be transparent about medical errors and bring such to discussion thereby finding solutions to avoid repeated occurrences.

The duty of care which is a doctrine that is common to all the health care professions makes leadership accountability a prime responsibility (by a general consent) and a necessity to be reposed in one member of the team who would be officially bound to coordinate others to work towards the protection of the patient. Since the principle of self-ownership (which is the possessive aspect of ownership) reserves ownership of the patient in the hands of the patient and this is already legally recognized in the concepts of assault and battery [15], if ownership is to be contemplated on at all it should not be possessive ownership of the patient and not by any one professional group or individual. Rather leadership accountability similar to altruism as enshrined in the duty of care and which all health care practitioners pledge to uphold, should be the concern of all in the health care process. At the same time all the health care practitioners, especially of the medical and nursing professions have to agree at every point in the health care process which one of their individual members should take prime responsibility (leadership) for the accountability of the team. Failure to have this agreement leaves room for no one member or professional group to be wholly accountable or to claim responsibility for the team. In other words, leadership in the health care process rather than ownership of the patient should be the concern for all.

\section{Is There Altruism in A Profession's Claim for Ownership of the Patient?}

Altruism, which is the selfless concern for the welfare of others even in the event of a disadvantage to the concerned person or group is a trait of service to the public not to a professional group or to an individual. McFubara and Pauley [16] have called for affective traits such as altruism or the public interest to be sought early in the admission process from potential medical students. This is because according to Millerson, [17] professions that claim to be altruistic have that trait as the core of their characteristic. But Elliott writing in 1972 [17] argued that the emphasis on the relationship between altruism and professionalism did not continue after the Second World War. In other words, since the 1950s service orientation among professional groups have not shown or demonstrated altruism. Although Saks [17] had suggested that occupational associations can take advantage of their altruistic feature to serve the public interest better, the opposite has been the case. For instance, in medical education at the undergraduate level all departments of medicine collaborate, that is they work in the interest of the student to ensure qualitative medical training. This is on the premise that at the end of such training no single department of medicine can claim ownership of the young medical graduate. The same is expected to apply in health care practice. But this has not been so, as specialties guard against 'territorial encroachment' bringing about intra- and inter-professional conflicts. In the face of such professional rivalries within the health sector, McFubara [18] has suggested an inter-professional collaborative education programme for the health care professions. This could be a major way by which the health care professions collectively can imbibe and demonstrate altruism.

In the gospel of John chapter 10 verse12 (The Bible, KJV) Jesus illustrates altruism in the concept of ownership with the relationship between a shepherd and the sheep on one hand and the same relationship between a hireling and the sheep on the other. In the case of the Shepherd, the owner, even in the face of danger and deprivation goes on to protect his own. But the hireling sees danger and deprivation and runs away for his dear life. Indeed, the latter is often demonstrated when patients are abandoned or discharged prematurely from the hospitals during industrial action by health sector workers. It is a wonder therefore who really owns the patient. Although Consultants are not expected to go on strike even when NMA members go on strike, a claim for ownership of the patient by the consultants even when patients are being prematurely discharged from hospital beds, under their noses, does not make sense. In the United Kingdom the General Practitioner has a more respectable status than the hospital consultant because it is the GP that refers the patient to the consultant and the patient 


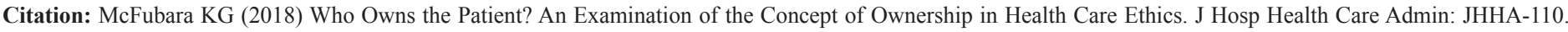
DOI: $10.29011 /$ JHHA-110. 00010

must be returned back to the GP. In that case a possible protective owner of the patient cannot be in doubt.

\section{Conclusion}

If ownership of the patient must be claimed in the health sector it must be a shared responsibility of ownership among members of the health team in the spirit of partnership among all stakeholders. And so as much as the prime responsibility for protective ownership of the patient can be seen to reside in one member of the health team, the leader, others however, cannot be isolated or isolate themselves from the process. This is because all health sector workers like any other workers provide service with the consent of or in contractual agreement with their patient or employer. And since that is the case, no individual or a professional group has the moral basis upon which to claim ownership of that which they are hired to service and protect. To think otherwise whether in the disguise of altruism or protecting patient interest will amount to a breach of their legal responsibility and obligation. Conflicts in the health sector can also be avoided if practitioners would be guided by history which shows that modern medical practice was started by the philosophers and that it is primarily morals that govern health care practice. Thus rather than think about ownership of the patient health care professionals should be concerned about effective leadership in the health care process for the safety or protection of the patient. In addition, there is the need for all health professional groups to have the patient instead of my patient in their induction oaths/pledges. This would ensure a proper recognition of the patient as his own owner, who must also be accorded due respect.

\section{References}

1. Ogbabo W (2014) We have not suspended the NMA Strike.

2. Brock DM, Saks M (2015) Professions and Organizations: A European Perspective. European Management Journal.

3. Parkin F (1979) Maxism and Class theory: A bourgeois critique. London: Tavistock.

4. Mosby's Dictionary: Medical, Nursing \& Allied Health (1990). $3^{\text {rd }}$ Edition.
5. Jensen R (1998) Man as Patient. In: Lammers SE and Verhey A (ed.). On Moral Medicine: Theological Perspectives in Medical Ethics. $\left(2{ }^{\text {nd }} e-\right.$ dition), Cambridge: William B. Eerdmans Publishing Company.

6. Rahner KSJ (972) Theological Investigations IX (Darton Longman and Todd, London). P. 228 cited by Boyd, K, Callaghan, B. SJ and Shotter E. (1986) Life Before Birth: Consensus in Medical Ethics. London:SPCK, p. 142.

7. Gibson KJ (2012) Killer Doctors: The Ultimate Betrayal of Trust. Neil Wilson Publishing.

8. Sulmasy DP (1998) Exousia: Healing with Authority in the Christian Tradition. In: Lammers SE and VerheyA (ed.). On Moral Medicine: Theological Perspectives in Medical Ethics $\left(2^{\text {nd }}\right.$ edition), Cambridge: William B. Eerdmans Publishing Company: 756-770

9. Uzodike VO (1998) Medical Ethics: Its Foundation, Philosophy and Practice, Enugu: Amazing Grace Printing and Publishing Coy. Chapter four.

10. Ayodele JA (2015) The Realties surrounding the applicability of Medical Paternalism in Nigeria. Global Journal of Social Science 14: 55-61.

11. Maxson, G (1998) Whose Life Is It, Anyway? Ours, That's Whose! In: Lammers SE and Verhey A (ed.). On Moral Medicine: Theological Perspectives in Medical Ethics ( $\left.2{ }^{\text {ndedition}}\right)$, Cambridge: William B. Eerdmans Publishing Company.

12. GMC (2017) Working with Doctors, Working with Patients.

13. Verstappen W, Gaal S, Esmail A, Wensing M (2015) Patient Safety Improvement Programmes for Primary Care. Review of Delphi procedures and pilot studies by LINNEAUS Collaboration on Patient Safety in Primary Care. Eur J Gen Pract 21: 50-55.

14. Klemp K, Zwart D, Hansen J, Hellebek T, Luettel D, et al. (2015) A Safety Incident Reporting System for Primary Care. A systematic literature review and consensus procedure by the LINNEAUS Collaboration on patient safety in primary care. Eur J Gen Pract 21: 39-44.

15. Mason JK, McCall SRA (1991) Law and medical Ethics $3^{\text {rd }}$ ed. London: Butterworths Chapter 10

16. McFubara KG, Pauley FG (2016) Medical Education: Need for Affective traits in medical school admission policy in Nigeria. Niger Delta Journal of Education, 8: 255-265, conference edition.

17. Saks M (1995) Professions and the Public Interest: Medical Power, Altruism and Alternative Medicine. London: Routledge.

18. McFubara KG (2014) Professional rivalry and patient safety in Nigeria. Journal of the Institute of Health Service Administrators of Nigeria, 18 35-40. 